\title{
Unconstrained Optimization of Single Variable Problems Using Interval Analysis
}

\author{
Neha Varma ${ }^{1}$, Ganesh Kumar $^{2}$ \\ I (NET-JRF, Department of Mathematics, B.R.A. Bihar University, Muzaffarpur, Bihar, India) \\ ${ }^{2}$ (University Professor\& Ex-H.O.D. of Mathematics, B.R.A. Bihar University, Muzaffarpur, Bihar, India)
}

\begin{abstract}
In this paper optimal solution of unconstrained single variable problems has been proposed using Newton's interval analysis method. Usually unconstrained single variable problems are solved in differential calculus using elementary theory of maxima and minima. Here nonlinear unconstrained problems have been taken whose derivatives are also non linear.
\end{abstract}

Keywords: Interval analysis, Interval expansion, Newton's method, Optimization, Unconstrained single variable problems.

\section{Introduction}

Interval analysis method was evolved in 1950-1960s on the advent of computational mathematics (pioneering work in the University of Karlsruhe). Problems containing a single variable are called onedimensional or univariate. The optimum of a function of single variable $f(x)$ occurs at a point where the first derivative of $\mathrm{f}(\mathrm{x})$ equals to zero. This point is known as critical point or stationary point. It is usually not very easy to solve the equation $\mathrm{f}^{\prime}(\mathrm{x})=0$ analytically. So here we opt for interval analysis method for finding the roots of the equation

$$
f^{\prime}(x)=0 .
$$

Interval analysis is a means of representing uncertainty by replacing single (fixed- point) values with intervals.

\subsection{Interval Arithmetic:}

Let $\tilde{\mathrm{x}}=\left[\mathrm{x}_{1}, \mathrm{x}_{2}\right], \tilde{\mathrm{y}}=\left[\mathrm{y}_{1}, \mathrm{y}_{2}\right]$

(i) Addition:

$$
\tilde{\mathrm{x}}+\tilde{\mathrm{y}}=\left[\mathrm{x}_{1}+\mathrm{y}_{1}, \mathrm{x}_{2}+\mathrm{y}_{2}\right]
$$

(ii) Subtraction:

$$
\tilde{\mathrm{x}}-\tilde{\mathrm{y}}=\left[\mathrm{x}_{1}-\mathrm{y}_{2}, \mathrm{x}_{2}-\mathrm{y}_{1}\right]
$$

(iii)Multiplication:

$$
\tilde{\mathrm{x}} . \tilde{\mathrm{y}}=\left[\min \left(\mathrm{x}_{1} \mathrm{y}_{1}, \mathrm{x}_{1} \mathrm{y}_{2}, \mathrm{x}_{2} \mathrm{y}_{1}, \mathrm{x}_{2} \mathrm{y}_{2}\right), \max \left(\mathrm{x}_{1} \mathrm{y}_{1}, \mathrm{x}_{1} \mathrm{y}_{2}, \mathrm{x}_{2} \mathrm{y}_{1}, \mathrm{x}_{2} \mathrm{y}_{2}\right)\right]
$$

(iv)Division:

$$
\frac{[a, b]}{[c, d]}=[\mathrm{a}, \mathrm{b}] .\left[\frac{1}{d}, \frac{1}{c}\right] \quad \text { if } 0 \notin[\mathrm{c}, \mathrm{d}]
$$

(v) $\lambda \tilde{\mathrm{x}}=\left[\lambda \mathrm{x}_{1}, \lambda \mathrm{x}_{2}\right]$ for $\lambda \geq 0$

$$
\left[\lambda \mathrm{x}_{2}, \lambda \mathrm{x}_{1}\right] \text { for } \lambda<0
$$

(vi)Inverse:

$$
\begin{array}{rlrl}
{\left[\mathrm{x}_{1}, \mathrm{x}_{2}\right]^{-1}} & =\left[\frac{1}{\mathrm{x}_{2}}, \frac{1}{x_{1}}\right] & , \text { for } 0 \notin\left[\mathrm{x}_{1}, \mathrm{x}_{2}\right] \\
\text { (vii) }\left[\mathrm{x}_{1}, \mathrm{x}_{2}\right]^{\mathrm{n}} & =\left[\mathrm{x}_{1}{ }^{\mathrm{n}}, \mathrm{x}_{2}{ }^{\mathrm{n}}\right], & \text { if } \mathrm{x}_{1} \geq 0 \\
& =\left[\mathrm{x}_{2}{ }^{\mathrm{n}}, \mathrm{x}_{1}{ }^{\mathrm{n}}\right], \text { if } \mathrm{x}_{2}<0 \\
& =\left[0, \max \left\{\mathrm{x}_{1}{ }^{\mathrm{n}}, \mathrm{x}_{2}{ }^{\mathrm{n}}\right\}\right] \text { otherwise. }
\end{array}
$$

\section{Newton's Method}

Let us consider one dimensional optimization problem

Minimize $\mathrm{f}(\mathrm{x})$

s.t. $a \leq x \leq b$

where $\mathrm{f}$ is continuously differentiable function.

The problem of minimizing $\mathrm{f}(\mathrm{x})$ is equivalent to obtaining the root of non-linear equation

$$
\mathrm{f}^{\prime}(\mathrm{x})=0
$$

because this is the necessary condition for extremum of $f$. This method consists of linearizing $\mathrm{f}^{\prime}(\mathrm{x})$ about a point $\mathrm{x}=\mathrm{x}_{\mathrm{k}}$ and then the point $\mathrm{x}_{\mathrm{k}+1}$ is given by 


$$
\mathrm{x}_{\mathrm{k}+1}=\mathrm{x}_{\mathrm{k}}-\frac{\mathrm{f}^{\prime}(\mathrm{xk})}{\mathrm{f}^{\prime \prime}(\mathrm{xk})}
$$

This procedure is only applicable for twice differentiable functions and the procedure is well defined only if $\mathrm{f}^{\prime \prime}\left(\mathrm{x}_{\mathrm{k}}\right) \neq 0$.

It has a rate of convergence of order two i.e. quadratic.

\section{Interval Newton Method}

Given a real valued function $f(x)$ defined on $X$ in $R$, if $f$ attains its maximum or minimum at a point $\mathrm{x}_{0} \in \mathrm{X}$, then the roots of $\mathrm{f}^{\prime}(\mathrm{x})=0$ can be calculated by using Newton's interval method for optimal solution.

In this method when changing from fixed- point to interval based root finding, there are some immediate differences. The root is no longer a crisp interval since iterations using an interval valued function produce intervals. For details of the math and convergence properties of the algorithm, refer to Kulisch et al. (2001). The algorithm is as follows:

$$
\begin{array}{ll}
X_{k+1}=X_{k} \cap N\left(X_{k}\right) \\
\text { where } \quad N\left(X_{k}\right)=m\left(X_{k}\right)-\frac{f\left(m\left(X_{k}\right)\right)}{f^{\prime}\left(X_{k}\right)}, \text { with } f^{\prime}\left(X_{k}\right) \neq 0
\end{array}
$$

Here $\mathrm{X}$ 's are intervals, $\mathrm{m}(\mathrm{X})$ is the midpoint of the interval $\mathrm{X}$, and $\mathrm{f}$ is the function whose root we seek (Kulisch et al. 35-36).

The similarity of this algorithm to the fixed-point Newton method is that a starting interval must be given and the interval size is decreased using a $\mathrm{f}(\mathrm{x}) / \mathrm{f}^{\prime}(\mathrm{x})$ term during iterations. This algorithm is almost as simple as the bisection method due to an easy convergence criterion.

\subsection{Example 1:}

The minimum value of the function $f(x)=x^{4}-48 x+12$ can be calculated by using Interval Newton method as follows:

Here $f(x)=x^{4}-48 x+12$

$$
\mathrm{f}^{\prime}(\mathrm{x})=4 \mathrm{x}^{3}-48=4\left(\mathrm{x}^{3}-12\right)
$$

To find the root of $\mathrm{f}^{\prime}(\mathrm{x})=4\left(\mathrm{x}^{3}-12\right)$ using Newton's interval method.

Let $\mathrm{F}=\mathrm{x}^{3}-12$

An interval expansion of $F^{\prime}=3 x^{2}$ is

$$
\mathrm{F}^{\prime}(\mathrm{X})=3 \mathrm{X}^{2}
$$

By Newton's interval formula, we have

$$
\begin{aligned}
X_{k+1}=X_{k} & \cap N\left(X_{k}\right) \\
\text { Where } N\left(X_{k}\right) & =m\left(X_{k}\right)-\frac{F(m(X)]}{F^{\prime}(X \kappa)}
\end{aligned}
$$

Let us take $\mathrm{X}_{0}=[2,4]$

$$
\begin{aligned}
& \text { Then } \mathrm{N}\left(\mathrm{X}_{0}\right)=\mathrm{m}\left(\mathrm{X}_{0}\right)-\left\{\frac{\left\{\left(m\left(X_{0}\right)\right)^{3}-12\right\}}{3\left(X_{0}\right)^{2}}\right\} \\
& =3-\frac{(27-12)}{3[2,4]^{2}} \\
& =[1.75,2.687] \\
& \mathrm{X}_{1}=[2,4] \cap[1.75,2.687] \\
& =[2,2.687] \\
& \text { Now, } \mathrm{N}\left(\mathrm{X}_{1}\right)=2.343-\frac{(12.870-12)}{3[2,2.687]^{2}} \\
& =[2.705,2.3030] \\
& \mathrm{X}_{2}=[2,2.687] \cap[2.705,2.3030] \\
& =[2.2705,2.3030]
\end{aligned}
$$

Hence the required root can be taken as the midpoint of this interval

$$
\text { i.e., } \quad \frac{2.2705+2.3030}{2}=2.28675
$$

Thus $\mathrm{f}(\mathrm{x})$ is minimum at $\mathrm{x}=2.28675$ where as elementary calculus method gives minima at $\mathrm{x}=2.28725$.

\subsection{Example 2:}

A square tank of capacity $250 \mathrm{~m}^{3}$ has to be dug out. The cost of land is Rs. $50 / \mathrm{m}^{2}$. The cost of digging increases with the depth and for the whole tank is $400(\text { depth })^{2}$ rupees. We have to find the dimensions of the tank for the least cost by Newton's interval method. 
Let $\mathrm{x}$ be the depth of the tank and $\mathrm{z}$ be the side of the square base.

Given that

Cost of digging $\propto$ depth

Given cost of digging for the whole tank $=400 \mathrm{x}^{2}$

Also, $250=\mathrm{z}^{2} \mathrm{x}$

$$
\mathrm{z}^{2}=\frac{250}{x}
$$

Total cost, $\mathrm{y}=\frac{12500}{x}+400 \mathrm{x}^{2}$

We have to minimize cost .

$$
\begin{aligned}
f^{\prime}(x) & =-\frac{12500}{x^{2}}+800 x \\
& =-100 x\left(\frac{125}{x^{3}}-8\right)
\end{aligned}
$$

To find the root of $\mathrm{f}^{\prime}(\mathrm{x})=-100 \mathrm{x}\left(\frac{125}{x^{3}}-8\right)$

Using Newton's interval method

Let $\mathrm{F}=\frac{125}{x^{3}}-8$

An interval expansion of $\mathrm{F}^{\prime}=-\frac{375}{x^{4}}$

Let us take $\mathrm{X}_{0}=[2,4]$

Then by Newton's interval formula,

$\mathrm{X}_{1}=\mathrm{X}_{0} \cap \mathrm{N}\left(\mathrm{X}_{0}\right)$
where $\mathrm{N}\left(\mathrm{X}_{0}\right)=\mathrm{m}\left(\mathrm{X}_{0}\right)-\frac{\mathrm{F}\left(\mathrm{m}\left(\mathrm{X}_{0}\right)\right]}{\mathrm{F}^{\prime}\left(\mathrm{X}_{0}\right)}$

$$
\begin{aligned}
& =3-\frac{\left(\frac{125}{27}-8\right)}{\frac{(-875)}{[2.4]^{4}}} \\
& =[0.6992,2.8563]
\end{aligned}
$$

$\mathrm{X}_{1}=[2,4] \cap[0.6992,2.8563]$

$=[2,2.8563]$

Proceeding in the same manner,

$$
\mathrm{X}_{2}=[2.4592,2.8563]
$$$$
\mathrm{X}_{3}=[2.422,2.525]
$$

Hence the required root can be taken as the midpoint of this interval, i.e.,

$$
\frac{2.422+2.525}{2}=2.47
$$

From eq. (i),

$$
\begin{aligned}
& z^{2}=\frac{250}{2.47}=101.215 \\
& z=10.06 \mathrm{~m}
\end{aligned}
$$

Thus the cost is minimum when the depth, $\mathrm{x}=2.47 \mathrm{~m}$ and the side of the square base, $\mathrm{z}=10.06 \mathrm{~m}$, It should be noted here that the elementary calculus method gives minimum cost for $\mathrm{x}=2.5 \mathrm{~m}$ and $\mathrm{z}=10 \mathrm{~m}$.

\section{Conclusion}

We have noticed that Interval Newton Method works efficiently in obtaining optimal solutions of even those problems whose derivatives are non linear. Also, the solutions obtained are better than those obtained by elementary calculus method.

\section{Acknowledgements}

To various scholars and G. Veeramalai, R.J. Sundararaj in particular, whose research papers motivated us in making this research paper.

\section{References}

[1] Karl Nickel, On the Newton method in Interval Analysis. Technical report 1136, Mathematical Research Centre,University of Wisconsion,Dec 1971.

[2] Louis B. Rall, A Theory of interval iteration, proceeding of the American Mathematics Society, 86z: 625-631, 1982.

[3] Hansen E.R (1978a), “Interval forms of Newton's method, Computing 20,153-163 
[4] K.Ganesan and P.Veeramani, On Arithmetic Operations of Interval Numbers, International Journal of Uncertainty, Fuzziness and Knowledge-Based system, 13(6) (2005), 619-631.

[5] R.E. Moore, Methods and Applications of Interval Analysis, SIAM Philadelphia, 1979.

[6] Moore, R.E.; Interval Analysis, New York: Prentice-Hall (1966). 